\title{
Oculoauriculovertebral spectrum and cerebral
} anomalies

Constance T R M Schrander-Stumpel, Christine E M de Die-Smulders, Raoul C M Hennekam, Jean-Pierre Fryns, Peter X J M Bouckaert, Oebele F Brouwer, Joost J da Costa, Ed J P Lommen, Petra D Maaswinkel-Mooy

\begin{abstract}
We report on three Dutch children with a clinical diagnosis of oculoauriculovertebral spectrum (OAVS) and hydrocephalus. The clinical features are compared to 15 published cases of OAVS and hydrocephalus. Several other cerebral abnormalities were present in the whole group. About half of the cases had cleft lip/ palate, anophthalmia/microphthalmia, or a cardiac defect. Mental retardation was found in five of the surviving 11 patients and early death occurred in onethird. We compared the cases with OAVS and hydrocephalus with published reports of OAVS and other cerebral anomalies and found no significant clinical differences. However, the clinical characteristics were clearly more severely expressed than generally found in patients with OAVS. Children with OAVS and more severe clinical features, especially anophthalmia/microphthalmia and cleft lip/palate, seem to be at an increased risk for cerebral malformations and for mental retardation.
\end{abstract}

In 1952, Goldenhar delineated a syndrome consisting of epibulbar dermoids, preauricular appendages, and mandibular hypoplasia. ${ }^{1}$ Gorlin et $a l^{2}$ extended the clinical features of this syndrome, reviewed published reports, and proposed the name 'oculoauriculovertebral dysplasia'. Many other terms have been used as well, such as hemifacial microsomia and Goldenhar syndrome. In the latest edition of Syndromes of the head and neck, Gorlin et al used the term 'oculo-auriculo-vertebral spectrum' (OAVS) because of the extreme complexity and heterogeneity of the condition. ${ }^{3} \mathrm{~A}$ wide range of anomalies has been described in this condition including unilateral or bilateral facial hypoplasia and ear and eye malformations. Vertebral, cardiac, and renal abnormalities may be part of the spectrum. ${ }^{4}$ As a minimal clinical sign microtia must be present. ${ }^{5}$

Cerebral anomalies and mental retardation have been described in OAVS. ${ }^{6-8}$ We had the opportunity to examine a newborn infant with OAVS and an extremely severe form of hydrocephalus. To the best of our knowledge, such severe cerebral abnormality in OAVS has not been reported before. Two other Dutch patients with OAVS and hydrocephalus were also examined. Here we present our three cases and review pertinent published reports.

\section{Case reports}

Patient 1, a male infant, was the first child of healthy, non-consanguineous Dutch parents. There were no miscarriages and the family history was negative for any congenital anomalies. However, the mother used 'soft' drugs. The pregnancy was complicated by polyhydramnios. Premature rupture of the membranes occurred at 29 weeks. Ultrasound examination at that time indicated hydrocephalus (fetal biparietal distance equivalent to 41 weeks and a grossly enlarged ventricular system, with 7 to $18 \mathrm{~mm}$ cerebral cortex visible). No additional malformations were found. The mother delivered spontaneously at 32 weeks' gestation; birth weight was $2165 \mathrm{~g}$ ( 75 th to 90 th centile). The severely deformed skull precluded reliable measurements of length and occipitofrontal circumference. There was bilateral facial hypoplasia, more pronounced on the left side, left sided anophthalmia, and right sided microphthalmia. In the right cornea and conjunctiva an epibulbar dermoid was present on the lower outer quadrant. Cleft lip and palate was present on the left side (fig 1). The mandible was very small and both ears were small and low set with multiple preauricular tags (fig 1). The hands and feet were normal. The child died shortly after birth. Necropsy disclosed no anomalies of the internal organs. Specific investigations of the eyes and brain were not performed. On the total body $x$ ray multiple cervical and thoracic vertebral abnormalities were seen. Chromosome investigation, performed on both cultured lymphocytes and fibroblasts, showed a normal male karyotype, 46,XY.

Patient 2 was the second male infant of healthy, non-consanguineous parents. There had been two miscarriages and the family history was negative for congenital abnormalities. At 26 weeks, ultrasonography because of polyhydramnios showed hydrocephalus and a breech position. After 42 weeks' gestation a male infant was born; birth weight was $3400 \mathrm{~g}$, length $50 \mathrm{~cm}$, and $O F C 38.7 \mathrm{~cm}$ (>97th centile). The right side of the face was hypoplastic. The depressor anguli oris muscle was underdeveloped on the right side (fig 2). The right ear was small, low set, and dysplastic (fig 2). He had a cardiac defect consisting of dextroposition and dextroversion of the heart, transposition of the great arteries, and a ventricular septal defect, which was overridden by a wide pulmonary artery. The ductus Botalli was wide with left to right shunting. Radiographs of the vertebral column showed no abnormalities and, apart from a convergent strabismus, 

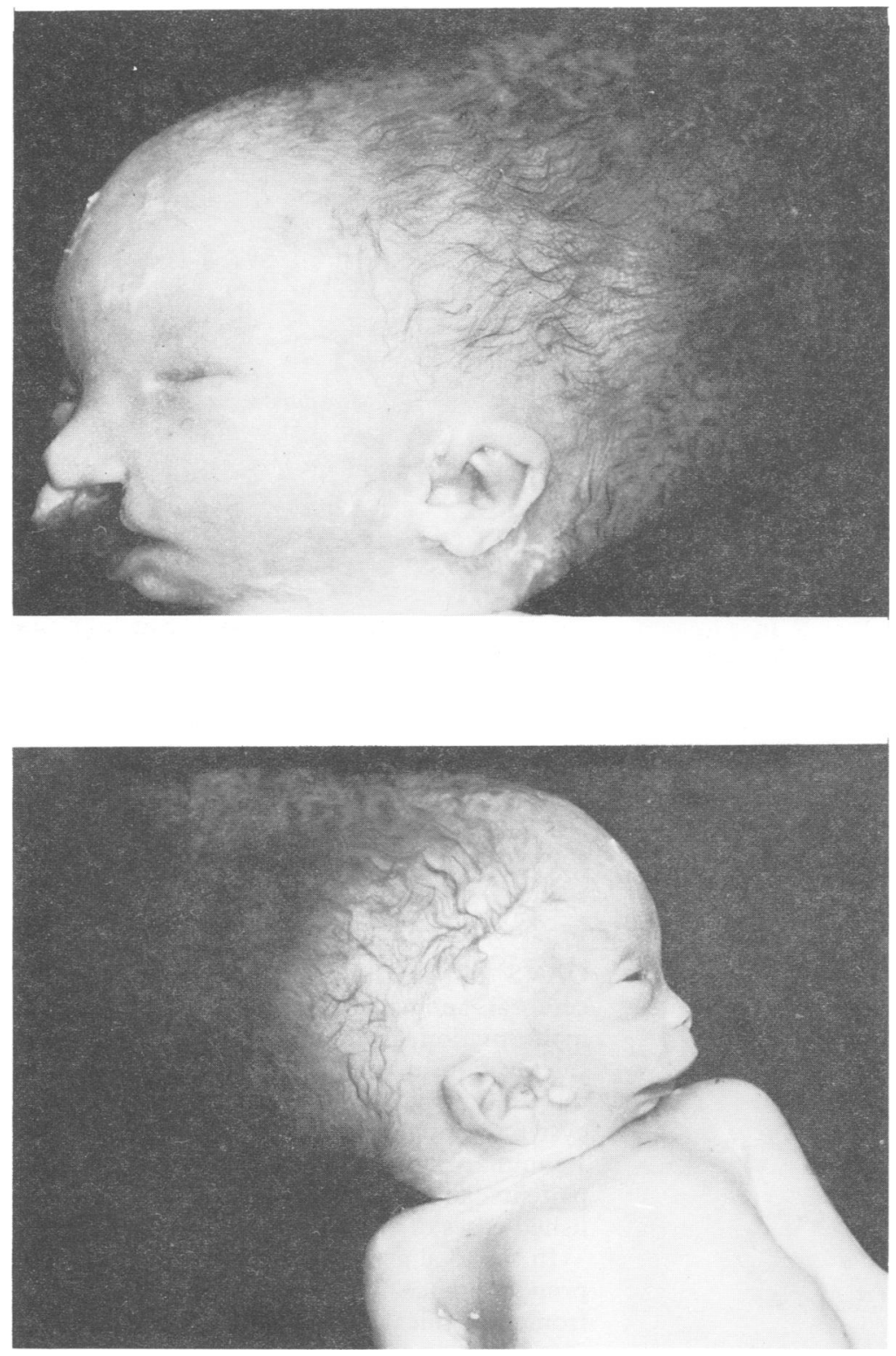

Figure 1 Patient 1: lateral views showing the hydrocephalic skull, left sided cleft lip/palate, micrognathia, low set, dysplastic ears and preauricular tags. there were no eye abnormalities. On cerebral CT scan supratentorial hydrocephalus and agenesis of the corpus callosum were found. Because of progressive increase of the head circumference a ventriculoperitoneal shunt was inserted. The patent ductus was surgically closed and the pulmonary artery was banded. His psychomotor development was not obviously delayed. After further cardiac surgery the infant suffered from septic shock and died at the age of 20 months. Necropsy was not performed. Cultured peripheral lymphocyte chromosomes were normal male, 46,XY.

Patient 3 was the first born male child of healthy, non-consanguineous parents. The family history was negative for any congenital abnormality. Conception took place during oral contraceptive use and was complicated by hypertension. At 35 weeks 5 days, the child was born weighing $1570 \mathrm{~g}$ (2nd to 3 rd centile), OFC $30 \mathrm{~cm}$ (2nd to 3 rd centile). Both ears were very small and dysplastic with preauricular tags and narrow outer auditory canals. On the left side of the face there was micrognathia and macrostomia (fig 3A). Ophthalmological examination showed no anomalies. The radius and thumb were absent on the right (fig 3B). The left ulna was hypoplastic and the left thumb was 'floating'. He had bilateral club feet. Other anomalies included a 'butterfly' third thoracic vertebra, 13 ribs, right sided hydronephrosis, a left kidney low in the pelvis, and an atrial septum defect of the heart. On cerebral ultrasound and magnetic resonance imaging the lateral ventricles and third ventricle were enlarged (fig 3C). At 3 months increasing ventricular diameter necessitated placement of a ventriculoperitoneal shunt. Hearing was impaired (brainstem evoked response bilaterally negative at $95 \mathrm{~dB}$ ). CT scan of the ears showed a total absence of the ossicles on the right side and on the left side only the incus was seen. The patient is now trained to hear using bone conduction. Motor development is mildly delayed owing to his
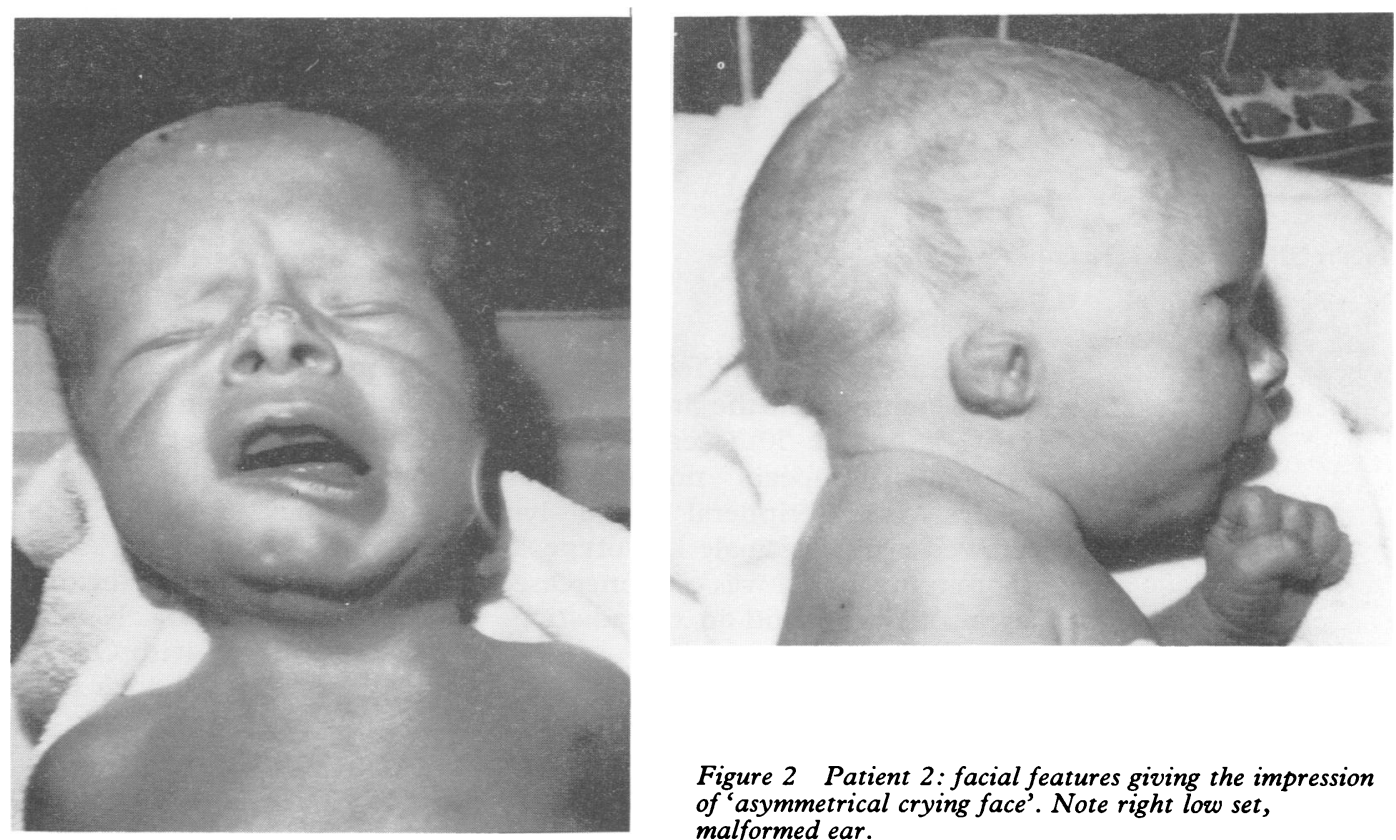

Figure 2 Patient 2: facial features giving the impression of 'asymmetrical crying face'. Note right low set, malformed ear. 


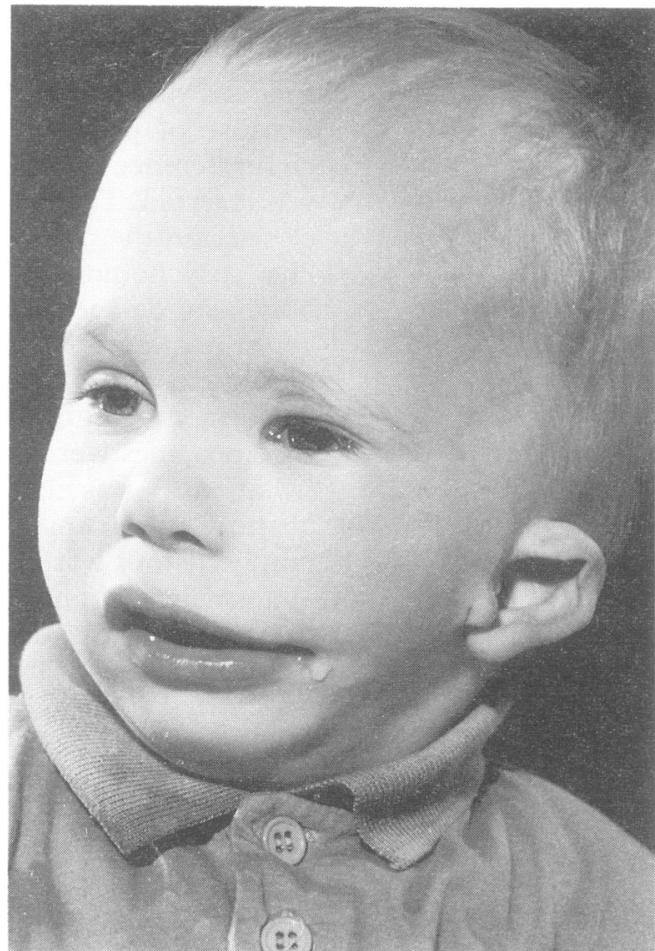

Figure 3A Patient 3: facial features at the age of 2 years showing the left sided macrostomia and malformed ear.

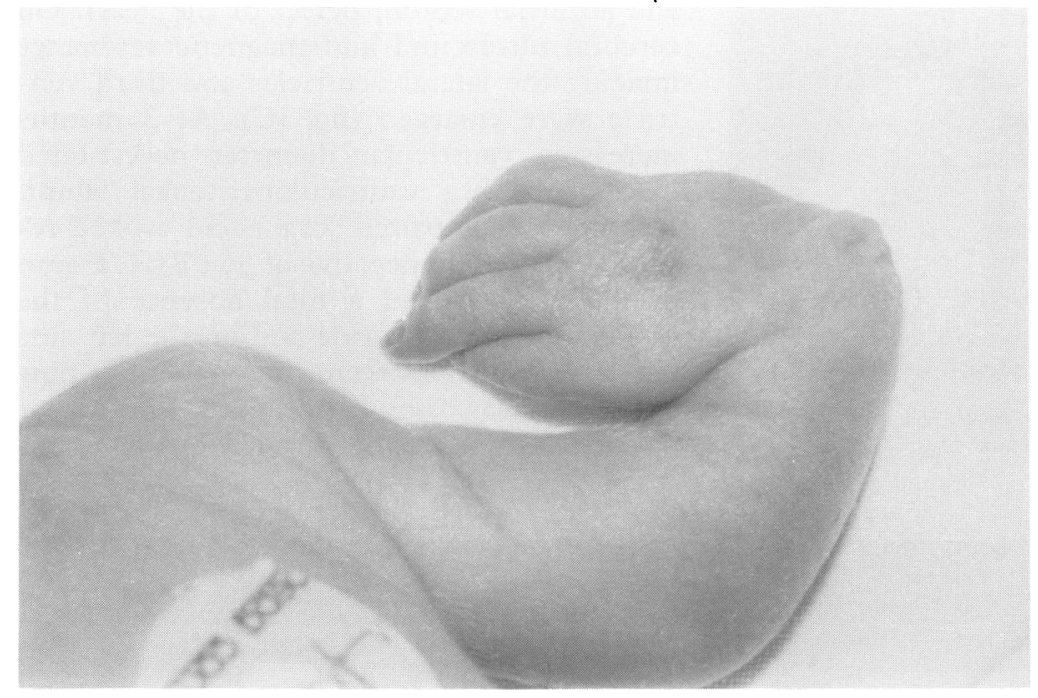

Figure 3B Patient 3: radial ray defect.

malformed hands and feet. At present, length and weight are on the 3rd to 10th centile and OFC is on the 50 th centile. His mental development appears normal. Chromosome analysis of peripheral blood lymphocytes showed a normal male karyotype. Sensitivity to mitomycin $\mathrm{C}$ was not increased and no breakage was found on $x$ irradiation.

\section{Review of previously published cases}

We were able to find at least 15 other published case histories of OAVS and hydrocephalus. $^{6-14}$ Of the total of 18 patients with

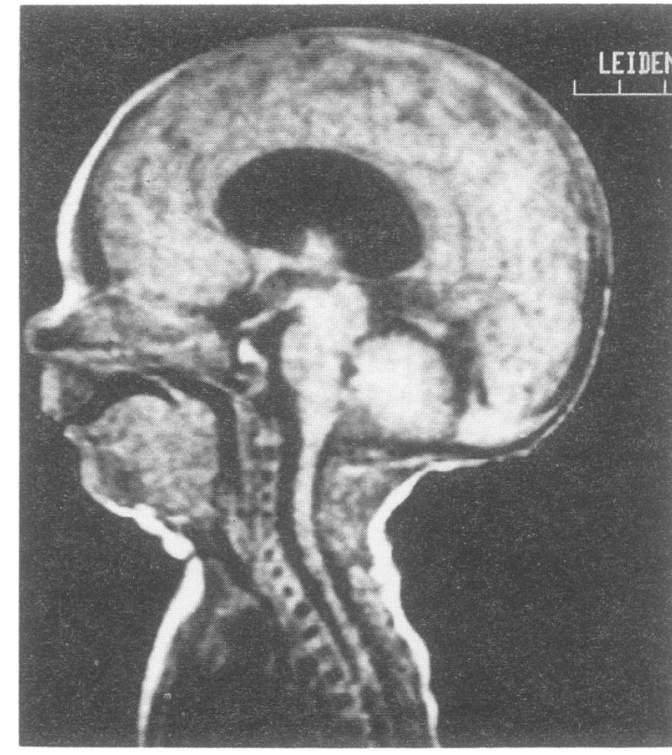

Figure 3C Patient 3: cerebral MRI at the age of 3 weeks showing considerable dilatation of the lateral ventricle. This results in a stretched and flattened corpus callosum. The occipital lobe is relatively prominent, which leads to an anterior displacement of the tentorium and sinus rectus. The contents of the posterior fossa indicate a relatively small cerebellum. The caudal part of the occipital bone is remarkably flattened.

OAVS and hydrocephalus several had other cerebral anomalies including Arnold-Chiari malformation, agenesis of the corpus callosum, calcification of the falx cerebri, hypoplasia of the septum pellucidum, intracranial dermoid cyst, and lipoma in the corpus callosum. Table 1 summarises the clinical features of our three patients and compares them with the published cases of OAVS and hydrocephalus.

In the total group, there was a striking male preponderance (M:F ratio $2: 1$ ). As expected from the clinical definition, all patients had ear anomalies and hydrocephalus. Facial hypoplasia (uni- or bilateral) (13/16), preauricular tags $(13 / 15)$, and vertebral anomalies $(9 / 11)$ were frequent findings. About half of the children had a uni- or bilateral cleft lip/palate (8/14), anophthalmia or microphthalmia (6/ $14)$, or a cardiac defect $(6 / 10)$. Mental retardation was reported in 5/13 surviving patients and early death was described in five infants (owing to cardiac surgery (two patients), respiratory distress syndrome (one child), or intrauterine/direct neonatal death (two infants)). Table 2 compares the clinical features in children with OAVS and hydrocephalus to those with other cranial defects and clinical features in OAVS in general. ${ }^{356}$ In the series of Rollnick $e t a l^{5}$ underestimation of the internal abnormalities may have been present since they based their study only on craniofacial features of OAVS. The comparison is further hampered by the different methods of describing the data. Nevertheless, the total group of children with OAVS and cerebral defects appears to show a higher frequency of bilateral ear abnormalities, cleft lip/palate, anophthal$\mathrm{mia} / \mathrm{microphthalmia,} \mathrm{vertebral} \mathrm{anomalies,} \mathrm{and}$ mental retardation when compared to children with OAVS in general. ${ }^{35} \mathrm{~A}$ clinical comparison 
Table 1 Clinical features of the present patients with OAVS and hydrocephalus compared to published cases.

\begin{tabular}{|c|c|c|c|c|c|c|}
\hline Manifestations & $\begin{array}{c}\text { Published } \\
\text { cases }^{6-14} \\
(n=15)\end{array}$ & Case 1 & Case 2 & Case 3 & Total & $\%$ \\
\hline \multicolumn{7}{|l|}{$\begin{array}{l}\text { Sex M/F } \\
\text { Facial hypoplasia }\end{array}$} \\
\hline Total & $10 / 13$ & & & & $13 / 16$ & \multirow{3}{*}{81} \\
\hline Unilateral & $8 / 13$ & & + & + & $10 / 16$ & \\
\hline Bilateral & $2 / 13$ & + & & & $3 / 16$ & \\
\hline \multicolumn{7}{|l|}{ Ear malformation } \\
\hline Total & $13 / 13$ & & & & $16 / 16$ & \multirow[t]{3}{*}{100} \\
\hline $\begin{array}{l}\text { Unilateral } \\
\text { Bilateral }\end{array}$ & $5 / 13$ & & + & & $6 / 16$ & \\
\hline \multicolumn{6}{|l|}{ Preauricular tags } & \\
\hline Total & $11 / 12$ & & & & $13 / 15$ & \multirow{3}{*}{87} \\
\hline Unilateral & $5 / 12$ & & & & $5 / 15$ & \\
\hline Bilateral & $6 / 12$ & + & - & + & $8 / 15$ & \\
\hline \multicolumn{7}{|l|}{ Epibulbar dermoid } \\
\hline Total & $9 / 15$ & & & & $10 / 18$ & \multirow[t]{3}{*}{56} \\
\hline Unilateral & $9 / 15$ & + & & & $10 / 18$ & \\
\hline Bilateral & $0 / 15$ & & - & - & $0 / 18$ & \\
\hline \multicolumn{7}{|l|}{ An-/microphthalmia } \\
\hline Total & $5 / 11$ & & & & $6 / 14$ & \multirow[t]{3}{*}{43} \\
\hline Unilateral & $4 / 11$ & & & & $4 / 14$ & \\
\hline Bilateral & $1 / 11$ & + & - & - & $2 / 14$ & \\
\hline \multicolumn{7}{|l|}{ Cleft lip/palate } \\
\hline Total & $7 / 11$ & & & & $8 / 14$ & \multirow[t]{4}{*}{57} \\
\hline Unilateral & $5 / 11$ & + & & & $6 / 14$ & \\
\hline Bilateral & $1 / 11$ & & - & - & $1 / 14$ & \\
\hline Cleft palate only & $1 / 11$ & & & & $1 / 14$ & \\
\hline Vertebral defects & $7 / 8$ & + & - & + & $9 / 10$ & 90 \\
\hline Cardiac defects & $4 / 7$ & - & + & + & $6 / 10$ & 60 \\
\hline Renal defects & $2 / 6$ & - & - & + & $3 / 9$ & 33 \\
\hline Hydrocephalus & $15 / 15$ & + & + & + & $18 / 18$ & 100 \\
\hline Additional CNS abnormalities* & $8 / 15$ & ? & $+\mathbf{a}$ & - & $9 / 17$ & 59 \\
\hline Mental retardation & $5 / 11$ & ? & - & - & $5 / 13$ & 38 \\
\hline Early death & $3 / 15$ & + & + & - & $5 / 18$ & 28 \\
\hline
\end{tabular}

* Calcified falx cerebri, ${ }^{9}$ Arnold-Chiari malformation, ${ }^{11}$ arachnoid cyst in the posterior fossa, ${ }^{13}$ a/hypoplasia of the septum pellucidum, ${ }^{61314}$ (partial) agenesis of the corpus callosum, ${ }^{714}$ lipoma of the corpus callosum, ${ }^{7}$ intracranial dermoid. ${ }^{6}$ $\mathrm{a}=$ agenesis of the corpus callosum.

Table 2 Clinical features of patients with OAVS and hydrocephalus compared to cases with OAVS and other cerebral defects and general cases with $O A V S .^{356, p r e s e n t ~ s t u d y ~}$

\begin{tabular}{|c|c|c|c|c|}
\hline Manifestation & $\begin{array}{c}\text { OAVS + } \\
\text { hydrocephalus } \\
\text { (present study) } \\
(n=18)(\%)\end{array}$ & $\begin{array}{l}\text { OAVS + other CNS } \\
\text { abnormality } \\
(n=13)(\%)\end{array}$ & $\underset{(\%)}{\text { Gorlin } e t} a l^{\beta}$ & $\begin{array}{c}\text { Rollnick et ap } \\
(\mathrm{n}=294)(\%)\end{array}$ \\
\hline $\begin{array}{l}\text { Ratio M:F } \\
\text { Facial hypoplasia } \\
\text { Unilateral } \\
\text { Bilateral } \\
\text { Ear malformation } \\
\text { Unilateral } \\
\text { Bilateral } \\
\text { Epibulbar tumour } \\
\text { Unilateral } \\
\text { Bilateral } \\
\text { An-/microphthalmia } \\
\text { Cleft lip/palate } \\
\text { Vertebral defects } \\
\text { Cardiac defects } \\
\text { Mental retardation }\end{array}$ & $\begin{array}{r}2: 1 \\
81 \\
77 \\
23 \\
100 \\
36 \\
64 \\
56 \\
100 \\
0 \\
43 \\
57 \\
90 \\
60 \\
38\end{array}$ & $\begin{array}{c}2.3: 1 \\
100 \\
? \\
? \\
100 \\
? \\
? \\
50 \\
? \\
? \\
70 \\
64 \\
73 \\
50 \\
100^{*}\end{array}$ & $\begin{array}{c}3: 2 \\
65 \\
67-90(62 \mathrm{R}) \\
10-33 \\
>65 \\
? \\
? \\
35 \\
50 \\
25 \\
\text { Rare } \\
7-15 \\
30 \\
5-58 \\
5-15(37)^{*}\end{array}$ & $\begin{array}{c}1.9: 1 \\
? \\
? \\
? \\
99 \\
65(62 \mathrm{R}) \\
34 \\
7 \\
? \\
? \\
? \\
22 \\
24 \\
5 \\
13^{*}\end{array}$ \\
\hline
\end{tabular}

* CNS abnormality and/or mental retardation.

with the cases described by Aleksic et al is not possible because this study focused only on cerebral and cranial features and mentioned few further clinical symptoms.

\section{Discussion}

The oculoauriculovertebral spectrum ${ }^{3}$ is a complex developmental field defect with wide phenotypic variation. Studying cases of OAVS is hampered by the lack of a clear 'standard' for OAVS and so by the uncertainty whether a case should be included or not. The spectrum includes microtia, preauricular tags, micrognathia, epibulbar dermoids, and vertebral anomalies. Additional features are renal and cardiac defects, cleft lip/palate, radial ray anomalies, skull abnormalities, cerebral defects, and mental retardation. The condition is aetiologically heterogeneous. The embryological timing is most likely around 30 to $\mathbf{4 5}$ days. It has been suggested that there could be a similar aetiological basis for all syndromes with overlapping features in the cranial (or caudal) region, such as Goldenhar syndrome, cardiofacial syndrome, and Wildervanck syndrome. The term 'axial mesodermal dysplasia spectrum' has been proposed. ${ }^{13} \mathrm{~A}$ disruption of vascular supply has been shown to be able to cause the clinical features of OAVS, even in familial cases. ${ }^{1516}$ The OAVS phenotype has been described in chromosomal defects, as summarised by Rollnick, ${ }^{17}$ and in exposure to teratogens such as primidone, thalidomide, and retinoic acid. ${ }^{18-20}$ OAVS has been described in infants born to mothers with diabetes and in syndromes of known or unknown cause, for instance Townes-Brocks syndrome. ${ }^{2122} \mathrm{~A}$ viral cause or overripeness of the fertilised egg have also been suggested. ${ }^{1023}$ In most cases, however, the cause remains obscure. 
The true incidence of central nervous system anomalies in persons with OAVS is not known, but it is not a rare manifestation of the spectrum. ${ }^{3}$ Wilson ${ }^{6}$ described six cases of OAVS and cranial defects and reviewed 12 published cases; five of these patients had hydrocephalus. Various bony defects may be present in OAVS including microcephaly, cranial asymmetry, platybasia, hypoplasia of the petrous and ethmoid bones, and absence of the internal auditory canals. ${ }^{6}$ The clinical findings in patients with OAVS and hydrocephalus are comparable to those in children with OAVS and other cerebral anomalies (table 2). Aleksic et $a l$ reported 13 patients with OAVS and diverse central nervous system anomalies, including five with hydrocephalus. The other clinical features were described only briefly. They reviewed central nervous system and neurological abnormalities in OAVS and found the spectrum of abnormalities to be very broad, ranging from involvement of the cranial nerves, hydrocephalus and increased intracranial pressure, occipital and frontal encephalocele, intracranial arachnoid cyst, intracranial lipoma, holoprosencephaly, hypoplasia of the corpus callosum, intracranial teratoma, lissencephaly, intracranial dermoid cyst, and Arnold-Chiari malformation to mental retardation.

Hydrocephalus in OAVS is frequently not further specified. In some cases stenosis of the aqueduct was specifically mentioned..$^{781014}$ The severity of hydrocephalus in patients with OAVS varies markedly, our patient 1 showing the most severe manifestation. In some patients no true hydrocephalus was present but successive periods of intracranial hypertension occurred, probably caused by a relative stenosis of the aquaduct of Sylvius, especially during periods of increased secretion of cerebral fluid, for instance during infections. ${ }^{824}$

Radial defects, as seen in patient 3 , are present in about $10 \%$ of patients with OAVS. ${ }^{325}$ Ulnar hypoplasia in the same child is not a common finding in the condition.

Patient 2 had hypoplasia of the depressor anguli oris muscle, giving the impression of a child with an asymmetrical crying face. He had a small, low set, and dysplastic ear on the right side and a complicated cardiac defect. The combination of a cardiac defect with facial asymmetry has been named cardiofacial syndrome. ${ }^{26}$ Not only cardiac defects, but also ear anomalies, vertebral abnormalities, and renal anomalies can be found with asymmetrical crying face. ${ }^{27}$ To our knowledge, cerebral anomalies like the hydrocephalus and agenesis of the corpus callosum present in patient 2 have not been reported. In our opinion, our second patient provides evidence that OAVS and cardiofacial syndrome (or asymmetrical crying face syndrome) are clinically closely related. The combination of OAVS and frontonasal dysplasia (FND) may represent the most severe form of the phenotype, ${ }^{1728}$ or may be a separate entity, renamed oculoauriculofrontonasal syndrome. ${ }^{29}$

Although Cohen $^{30}$ assumed a correlation between the severity of the cranial defects and the 'other' features in a patient with OAVS, Aleksic et al could not confirm a marked degree of correlation between the degree of facial hypoplasia and the severity of MR. Indeed, 3/13 cases had minimal facial involvement and marked central nervous system anomalies. In the experience of Rollnick et al, ${ }^{5}$ anomalies of the cervical vertebrae increased the likelihood of other anomalies.

The present study shows that the clinical manifestations of subjects affected with OAVS and hydrocephalus did not differ from those with OAVS and other cerebral abnormalities. However, comparing all cases of OAVS with cerebral anomaly to patients with OAVS in general, ${ }^{35}$ we found a strikingly higher frequency of bilateral ear anomalies, cleft lip/ palate, anophthalmia/microphthalmia, vertebral anomalies, and mental retardation. These features, especially anophthalmia/microphthalmia, may well be clinical markers for increased risk of cerebral malformation and mental retardation in a patient with OAVS.

The authors wish to thank the 'Werkgroep voor erfelijkheidsadviezen', Nijmegen, The Netherlands, for help in diagnosis in patient 2.

1 Goldenhar M. Associations malformatives de l'oeil et de l'oreille, en particulier le syndrome dermoide epibulbaireappendices auriculaires-fistula auris congenita et ses relations avec la dysostose mandibulo-faciale. $\mathcal{F}$ Genet Hum 1952;1:243-82.

2 Gorlin RJ, Jue KL, Jacobsen U, et al. Oculoauriculovertebral dysplasia. F Pediatr 1963;63:991-9.

3 Gorlin RJ, Pindborg JJ, Cohen MM. Oculoauriculovertebral spectrum. In: Syndromes of the head and neck. 3rd ed. New York: McGraw-Hill, 1989:641-9.

4 Jones KL. Facio-auriculo-vertebral spectrum. In: Smith's recognizable patterns of human malformation. Philadelphia: Saunders, 1988:584-6.

5 Rollnick BR, Kaye CI, Nagatoshi K, et al. Oculoauriculovertebral dysplasia and variants: phenotypic characterisvertebral dysplasia and variants: phenotypic characteris-

tics of 294 patients. Am $\mathcal{f}$ Med Genet $1987 ; 26: 361-75$.
6 Wilson GN. Cranial defects in the Goldenhar syndrome. Am $f$ Med Genet 1983;14:435-43.

7 Aleksic S, Budzilovich G, Greco MA, et al. Intracranial lipomas, hydrocephalus and other CNS anomalies in oculoauriculo-vertebral dysplasia (Goldenhar-Gorlin syndrome). Child's Brain 1984;11:285-97.

8 Metthey R, Masson G, Peyre MP, et al. Hydrocephalie et syndrome de Goldenhar. F Genet Hum 1987;35:275-7.

9 Christiaens L, Walbaum R, Farriaux JP, et al. A propos de deux cas de dysplasie oculo-auriculo-vertebrale. Pediatrie 1966;21:935-42.

10 Saule H, Ortlieb R. Goldenhar-Syndrom. Bericht uber einen fall mit hydrozephalus. Klin Padiatr 1973; 185:230-6.

11 Michaud C, Sheridan S. Goldenhar's syndrome associated with cranial and neurological malformations. Can $\mathcal{f} O p h-$ thalmol 1974;9:347-50.

12 Murphy MJ, Risk WS, VanGilder JC. Intracranial dermoid cyst in Goldenhar's syndrome. Case report. $\mathcal{f}$ Neurosurg 1980;53:408-10.

13 Russell LJ, Weaver DD, Bull MJ. The axial mesodermal dysplasia spectrum. Pediatrics 1981;67:176-82.

14 Thorbeck R. Goldenhar-syndrom und hydrozephalus. Monatschr Kinderheilkd 1982;130:47-9.

15 Robinson LK, Hoyme HE, Edwards DK, et al. Vascular pathogenesis of unilateral craniofacial defects. $\mathcal{f}$ Pediatr 1987;111:236-9

16 Hennekam RCM, Hofstee N. Familial liability to intrauterine vascular impairments. Pediatrics 1990;86:326.

17 Rollnick BR. Oculoauriculovertebral anomaly: variability and causal heterogeneity. Am $\mathcal{f}$ Med Genet 1988; suppl 4:41-53.

18 Gustavson EE, Chen H. Goldenhar syndrome, anterior encephalocele, and aquaductal stenosis following primidone exposure. Teratology 1985;32:13-17.

19 Livingston G. Congenital ear abnormalities due to thalidomide. Proc $R$ Soc Med 1965;58:493-7.

20 Lammer EJ, Chen DT, Hoar RM, et al. Retinoic acid embryopathy. N Engl f Med 1985;313:837-41.

21 Israel J, Vasan V, Dolezal E, et al. Goldenhar complex oculoauriculovertebral anomaly) in an infant of a diabetic: case report. Clinical Genetics Conference: neural crest and craniofacial disorders, Minneapolis, MN, 1988:195A.

22 Townes PL, Brocks ER. Hereditary syndrome of imperforate anus with hand, foot and ear anomalies. $\mathcal{f}$ Pediatr 1972;81:321-6. 
23 Jongbloet PH. Goldenhar syndrome and overlapping dysplasias, in vitro fertilisation and ovopathy. $\mathcal{f}$ Med Genet 1987;24:616-20.

24 Hennekam RCM, van Nieuwenhuizen O, Gooskens RH. Paroxysmal intracranial hypertension and oculoauriculovertebral dysplasia. $f$ Genet Hum 1989;37:437-8.

25 Moeschler J, Clarren SK. Familial occurrence of hemifacia microsomia with radial limb defects. Am $\mathcal{f}$ Med Genet 1982;12:135-41.

26 Cayler GG. Cardiofacial syndrome. Congenital heart disease and facial weakness, a hitherto unrecognized association. Arch Dis Child 1969;44:69-75.

27 Pape KE, Pickering D. Asymmetric crying facies: an index of other congenital anomalies. $\mathcal{F}$ Pediatr $1972 ; 81 \cdot 21-30$.
28 Cohen MM Jr. Selected clinical research involving the central nervous system. F Craniofac Genet Dev Bio 1990;10:215-38.

29 Golabi M, Gonzalez MC, Edwards MS. A new syndrome of oculo-auriculo-vertebral dysplasia and midline craniofacial defect: the oculo-auriculo-frontonasal dysplasia. Two new cases in sibs. Birth Defects Conference, 1982 (abstract)

30 Cohen MM. Variability versus "incidental findings" in the first and second brachial arch syndrome: unilateral variants with anophthalmia. In: Bergsma D, ed. The third conference on the clinical delineation of birth defects. Baltimore: Williams and Wilkins for the National FoundationMarch of Dimes. Birth Defects 1971;VII(7):103-8. 